Derecho \& Realidad

Núm. 22 • II semestre de 2013

Facultad de Derecho y Ciencias Sociales, UPTC

ISSN: 1692-3936

\title{
La ponderación en la resolución de colisiones de derechos fundamentales. Especial referencia a la jurisprudencia constitucional española*
}

\author{
Balance in resolution of collision of fundamental \\ rights. Special reference to the Spanish \\ constitutional jurisprudence
}

Ramón Ruiz Ruiz**

\section{Resumen}

Para el estudio de la ponderación en la resolución de colisiones de derechos fundamentales, especialmente en lo referente a la jurisprudencia constitucional española, es necesario entrar a ver la distinción entre reglas y principios: la tesis fuerte de la separación; a su vez, el papel de los principios en el razonamiento jurídico y por último, la colisión de derecho en la jurisprudencia constitucional española.

\section{Palabras clave}

jurisprudencia, ponderación, derechos fundamentales, teorías del derecho, principios y reglas, constitucionalismo español.

\footnotetext{
Este trabajo se inserta en el ámbito de las investigaciones llevadas a cabo en el marco del programa de investigación Consolider Ingenio 2010 "El tiempo de los derechos" (CDS 2008-00007).

** Integrante del Grupo de Investigación en Justicia Social Primo Levi.
} 


\section{Abstract}

For the study of the balance in the resolution of collision of fundamental rights, in particular concerning to the Spanish constitutional jurisprudence, is necessary to see the distinction between rules and principles: the strong thesis of separation; at the same time the role of the principles in legal reasoning and last, the law collision in Spanish constitutional jurisprudence.

Key words

jurisprudence, balance, fundamental rights, theories of law, principles and rules, Spanish constitutionalism. 


\section{Introducción}

Una de las cuestiones más profusamente discutidas en la teoría del derecho durante las dos últimas décadas, es la distinción entre reglas y principios. Conviene subrayar, antes de continuar, que tanto unas como otros tienen en común la característica de ser normas jurídicas, esto es, enunciados prescriptivos que ordenan, permiten o prohíben ciertas conductas humanas, si bien, como veremos, presentan significativas diferencias, en especial, atendiendo a su forma de aplicación y al modo en que es posible resolver situaciones de contradicción entre ellas. Por otra parte, como señala Zagrebelsky, "por lo general, las normas legislativas son reglas, mientras que las normas constitucionales sobre derechos y sobre la justicia son predominantemente, principios" (19995, p. 109) -aunque la Constitución también contiene reglas ${ }^{2}$, al tiempo que pueden encontrarse principios jurídicos fuera de ella ${ }^{3}-$.

No obstante, como se señalaba al principio, esta cuestión no es pacífica, sino que, muy al contrario, ha dado lugar a una gran polémica doctrinal respecto a cuáles sean las características de cada una de estas clases de normas o sobre los criterios de distinción; es más, hay quienes critican esta distinción o, al menos, su relevancia, como es el caso, por ejemplo, de L. Prieto Sanchís (1998).

Es cierto, como señalan Atienza y Ruiz Manero (1991, p. 101), que los “principios jurídicos" son viejos conocidos de los juristas; sin embargo, puede afirmarse que fue Ronald Dworkin, con su artículo “EEs el Derecho un sistema de reglas?” -posteriormente incluido, como segundo capítulo, en su obra Los derechos en serio (1995)- quien inició un debate, que aún continúa, con consecuencias, entre otras materias, en la dogmática y la metodología jurídicas, en el concepto de sistema jurídico, en la relación entre derecho y moral y en la argumentación jurídica.

Dworkin construye su teoría sobre la distinción entre reglas y principios como un ataque al positivismo jurídico y, especialmente, a la versión de H.L.A. Hart, a quien acusa de concebir el derecho como un sistema normativo compuesto exclusivamente por reglas, las cuales son identificadas como tales por la manera en que son adoptadas o desarrolladas (lo que Dworkin denomina su pedigree). Sin embargo, según aquel, cuando los juristas razonan, no solo utilizan reglas, sino también otro tipo distinto de normas como son los principios, algo que el positivismo

2 Por ejemplo, el artículo 17.2 de la Constitución española, que prescribe que "La detención preventiva no podrá durar más del tiempo estrictamente necesario para la realización de las averiguaciones tendentes al esclarecimiento de los hechos, y, en todo caso, en el plazo máximo de setenta y dos horas, el detenido deberá ser puesto en libertad o a disposición de la autoridad judicial".

3 Por ejemplo, en el artículo 7.1 del Código civil: "Los derechos deberán ejercitarse conforme a las exigencias de la buena fe". 
Derecho y Realidad

parece haber olvidado. La crítica de Dworkin es de gran relevancia, dado que ataca las dos tesis básicas del positivismo, a saber, la tesis de la separación conceptual entre derecho y moral y la tesis de la discreción judicial.

Conforme a la primera de estas tesis, la validez de una norma jurídica no depende de su bondad moral -ni de la bondad moral de una norma puede derivarse su validez jurídica-, sino de su conformidad con los criterios establecidos en lo que Hart denomina la "regla de reconocimiento". Sin embargo, para Dworkin esta tesis no se sostiene, puesto que el ordenamiento jurídico está integrado también por principios, cuya pertenencia al mismo no es determinada por la manera en que son creados (esto es, por su pedigree), sino por la adecuación de su contenido a la moral. Ciertamente, para Dworkin un principio es una norma que debe ser observada porque es una exigencia de la justicia, la equidad o alguna otra dimensión de la moralidad y, de hecho, la existencia de los mismos constituye una de las vías para la introducción de la moral en el derecho -constituyendo éste, por tanto, uno de los argumentos utilizados por los críticos del positivismo jurídico para rechazar la separación conceptual entre derecho y moral-.

No obstante, esta crítica al positivismo jurídico ha sido contestada ampliamente por distintos juristas. Así, como escribe Gregorio Peces-Barba, los valores, los principios y los derechos no son derecho si no se incorporan al sistema jurídico por las puertas por las que entra la moralidad en el derecho: el derecho legal y el derecho judicial. Por tanto, "no es evidente la contradicción entre principios y reglas, ni es necesaria la aproximación iusnaturalista de que existe Derecho al margen de lo que Hart llama la regla de reconocimiento y yo la norma fundante básica de identificación de normas. Por el contrario, aparece en la realidad que los principios, los valores y los derechos (...) no se imponen a la colectividad desde su verdad, desde la racionalidad, sino que los imponen los operadores jurídicos desde su autoridad (...). Ambos, principios y reglas, sólo son relevantes para el Derecho como Derecho, cuando la voluntad normativa, a través de los operadores jurídicamente habilitados, los incorpora al sistema. Ambos son pues, normas, aunque con contenidos y efectos diferentes en su acción del mecanismo del Derecho. Así se puede hablar de normas principio y de normas regla. No veo que esta interpretación ponga en entredicho el valor de una aproximación positivista" (PecesBarba, 1997, p. 13).

Por su parte, la tesis de la discrecionalidad judicial, según la cual cuando ninguna norma es aplicable a un caso concreto el juez es libre de ejercer su discreción para llegar a una solución, debe ser también rechazada a juicio de Dworkin por dos razones. Primero, porque supone una violación del principio de separación de poderes, ya que se le reconoce al poder judicial una capacidad de dictar normas que es exclusiva del poder legislativo; y, en segundo lugar, porque si esto fuera 
así, permitiría legislar ex post facto, ya que desde el momento en que se reconoce que el juez, en el ejercicio de su discrecionalidad, puede crear normas aplicables a un caso que no tiene una solución normativa por parte del sistema de fuentes, se está admitiendo la aplicación de una norma con carácter retroactivo, pues se trata de una norma que no existe en el momento en que se produjo el hecho (violándose, así, el principio nullum crimen sine lege praevia). Ambos problemas pueden ser solucionados si se reconoce la existencia de los principios jurídicos. En efecto, la existencia de éstos demuestra que el juez no goza de discrecionalidad ni siquiera en aquellos casos en los que hay oscuridad, vaguedad o ausencia de reglas aplicables, ya que siempre va a poder recurrir a un principio del ordenamiento jurídico. De este modo, no existe discreción judicial, sino que para cualquier caso que se plantee, el sistema jurídico, compuesto por reglas y principios, ofrece una respuesta correcta.

\section{La distinción entre reglas y principios: la tesis fuerte de la separación}

En cualquier caso, la cuestión de la distinción entre reglas y principios puede ser abordada desde dos perspectivas o enfoques diferentes: el estructural y el funcional. Este segundo, conforme a Atienza y Ruiz Manero (1996, p. 11-15) se centra en el papel o la función que las normas cumplen en el razonamiento práctico de sus destinatarios. Por su parte, conforme al enfoque estructural, que es el que aquí nos interesa, la distinción puede plantearse de la siguiente manera: "aceptado que las reglas pueden formularse siempre recurriendo a un esquema condicional, esto es, de correlación caso/solución (...) ¿puede decirse lo mismo de los principios?; esto es, se trata de ver si los principios tiene la misma estructura condicional y/o (sic) si los operadores deónticos que rigen para las reglas son los mismos que los de los principios" (Atienza \& Ruiz Manero, 1991, p. 107).

Respecto a esta cuestión, Aulis Aarnio (2000, p. 539) sostiene que las opiniones sobre la distinción estructural entre reglas y principios pueden ser divididas, a grandes rasgos, en dos tesis principales. Por un lado, la "tesis débil de la separación", según la cual, entre reglas y principios existe una diferencia de grado, no cualitativa y desempeñan un papel similar o análogo en el discurso jurídico; generalmente, sostienen sus partidarios, los principios tienen una mayor generalidad que las reglas, pero por lo demás no hay especiales características para distinguirlos de ellas, sino tan sólo distintos modos de interpretarlos y aplicarlos. Conforme a la "tesis fuerte de la separación", en cambio, la diferencia entre reglas y principios no se refiere, exclusivamente, al grado de generalidad, sino que es más bien cualitativa, esto es, por su estructura, reglas y principios pertenecen a categorías diferentes, pues son estructuralmente distintos. Me centraré en esta segunda tesis, toda vez que, como tendremos ocasión de comprobar, es la que más se ajusta al modo como se suelen resolver las colisiones entre derechos fundamentales. 
Robert Alexy (1997, p. 81-98), uno de los más destacados exponentes de esta tesis fuerte de la separación, señala que la distinción entre reglas y principios es vital para la teoría de los derechos fundamentales, pues sin ella no puede existir una teoría satisfactoria de la colisión y tampoco una teoría suficiente acerca del papel que juegan los derechos fundamentales en el sistema jurídico.

Para Alexy, un punto decisivo para la distinción entre reglas y principios radica en que éstos son normas que ordenan que algo sea realizado en la mayor medida de lo posible, dentro de las posibilidades jurídicas y fácticas existentes. Es decir, los principios son "mandatos de optimización", caracterizados por el hecho de que pueden ser cumplidos en diferente grado y en la medida de que su cumplimiento no sólo depende de las posibilidades fácticas, sino también de las jurídicas -el ámbito de las posibilidades jurídicas estaría determinado por los principios y las reglas opuestos-. En cambio, las reglas, serían "mandatos definitivos" o, lo que es lo mismo, normas que sólo pueden ser cumplidas o no: si una regla es válida, entonces debe hacerse exactamente lo que ella exige, ni más ni menos. Todo esto demostraría que la diferencia entre reglas y principios es cualitativa y no de grado.

Ahora bien, la distinción entre reglas y principios se muestra clarísimamente en los supuestos de colisión de principios y de conflicto de reglas. En ambos casos, cada una de las normas implicadas, si se aplican independientemente, conducen a resultados incompatibles, es decir, a dos juicios de deber ser jurídico contradictorios; sin embargo, existen diferencias en la forma como se soluciona el conflicto.

Para analizar este segundo criterio de distinción, Alexy recurre a dos decisiones del Tribunal Constitucional alemán. La primera se refiere a un conflicto entre una norma jurídica del Estado Federal y una norma de un Land (BverfGE, 1, 283 (292). Esta última prohibía la apertura de puestos de venta los miércoles desde las 13 horas, mientras que la norma federal lo permite hasta las 19 horas. Este es un caso clásico de conflicto de reglas contradictorias: una permite lo que la otra prohíbe, de modo que si ambas fueran válidas, la apertura los miércoles por la tarde estaría tanto permitida como prohibida. Se trata de un conflicto que sólo puede ser solucionado o bien introduciendo en una de las reglas una cláusula de excepción que elimine el conflicto o bien declarando inválida una de las reglas. Así, el Tribunal resolvió este caso según la norma de conflicto "el Derecho federal prevalece sobre el Derecho del Land" (art. 31 de la Ley Fundamental de Bonn), declarando, así, nula la norma jurídica del Land.

Otro ejemplo de conflicto de reglas que puede ser solventado a través de la introducción de una cláusula de excepción es aquel que se da entre la prohibición de abandonar una sala antes de que suene el timbre de salida y la orden de abandonarla en caso de que se escuche la alarma de incendios. Si todavía no ha sonado el timbre 
de salida y se da la alarma, estas reglas conducen a juicios concretos de deber ser contradictorios entre sí. El conflicto se puede solucionar introduciendo en la primera regla una cláusula de excepción para el supuesto de que suene la alarma de incendios. Ahora bien, si una solución de este tipo no es posible, por lo menos una de las reglas tiene que ser declarada inválida y, con ello, eliminada del ordenamiento jurídico. Ciertamente, a diferencia de lo que sucede con el concepto de validez social, el concepto de validez jurídica no es graduable: una norma vale o no vale jurídicamente.

De manera enteramente distinta procede el Tribunal Constitucional alemán en una decisión sobre la celebración de un juicio oral contra un inculpado al que amenaza el peligro de un ataque de apoplejía y de infarto (BverfGE, 51, 324). Las normas en colisión son, por un lado, el artículo 2.2 de la Ley Fundamental de Bonn, que reconoce al individuo un derecho fundamental a la vida y a la integridad física y, por otro, el principio que impone al Estado el deber de garantizar un eficiente funcionamiento de las instituciones del derecho penal. Si existiera sólo el derecho fundamental, entonces la celebración de un juicio oral que pusiera en peligro la vida y la salud de un inculpado habría que calificarla, sencillamente, de prohibida; si existiera sólo el deber del Estado de cuidar de un eficiente funcionamiento de las instituciones jurídicas, entonces habría que considerar el juicio oral, simplemente, como obligatorio o, cuando menos, permitido. Por otro lado, si el Tribunal hubiera resuelto el caso eliminando del ordenamiento jurídico bien el derecho fundamental o bien el deber, habría tratado la colisión de las correspondientes normas como una contradicción y, por ello, como un conflicto de reglas. El proceder del Tribunal, sin embargo, es de un tipo enteramente distinto: no habla de una contradicción entre ambas normas, sino de una tensión y subraya que ninguna de ellas goza "simplemente de primacía frente a la otra", lo que sería el caso si una de las normas, como en los supuestos de conflictos de reglas, hubiese sido declarada inválida.

En efecto, las colisiones entre principios deben ser solucionadas de manera totalmente distinta. Cuando dos principios entran en colisión, uno de ellos tiene que ceder ante el otro; pero esto no significa declarar inválido al principio desplazado, ni que en éste haya que introducir una cláusula de excepción, puesto que, bajo ciertas circunstancias, la cuestión de la precedencia puede ser solucionada de manera contraria. Esto es lo que se quiere decir cuando se afirma que en cada caso concreto los principios tienen diferente peso y que prima el principio con mayor peso. Estos casos han de ser resueltos a través de una ponderación, con lo cual el factor decisivo lo constituye el principio al que le corresponde un peso relativamente mayor en el caso concreto; al principio que juega en sentido contrario se le hace retroceder, pero no se declara inválido. En definitiva, "los conflictos de reglas se llevan a cabo en la dimensión de la validez; la colisión de principios -como sólo pueden entrar 
en colisión principios válidos- tiene lugar más allá de la dimensión de validez, en la dimensión del peso".

\section{El papel de los principios en el razonamiento jurídico}

Seguramente, la principal consecuencia que se deduce de la aplicación de los principios y de la técnica de la ponderación es el fortalecimiento de la posición del juez, pues allí donde aparece un conflicto entre dos principios (o dos derechos), surge una decisión que otorga preferencia a uno u otro y que va a tener como único límite la racionalidad ${ }^{4}$. No obstante, como señala Prieto Sanchís (2000, p. 173), por mucha fe que se tenga en la argumentación racional, parece que la aplicación de principios comporta mayores riesgos de subjetividad valorativa que la aplicación de reglas.

No cabe duda -sostiene el citado profesor (Prieto Sanchís, 1998, p. 61-63)- de que, a la hora de aplicar principios, el juez es mucho más protagonista y, por tanto, más libre, que en la aplicación de reglas según el modelo tradicional. Y, lo que es más importante, la ponderación no solo aparece cuando estamos en presencia de un conflicto explícito entre principios o derechos, sino que puede recurrirse a ella siempre que el resultado de la aplicación de reglas le parezca al intérprete insatisfactorio o injusto, pues la técnica de los principios es aplicable siempre, y no sólo en presencia de enunciados normativos dotados de ciertas características, toda vez que siempre está al alcance del juez transformar en principios las reglas que sustentan la posición de cada parte. En esta línea, advierte Guastini (1999, p. 40) que la identificación de un principio en cuanto tal -siempre que se trate de disposiciones que no estén expresamente etiquetadas como principio por la propia autoridad normativa-, comporta discrecionalidad, pues a menudo, si bien no siempre, una misma disposición normativa puede ser interpretada como una regla o como un principio.

No obstante, son muchos quienes opinan que cuando se aplican principios, si bien no es fácil sostener que existe una única respuesta correcta, sí que, al menos, existen unos ciertos mecanismos para reducir al máximo la discrecionalidad judicial. Así, Alexy (1988, p. 139) disiente de la tesis de Dworkin, según la cual los principios jurídicos deben permitir que también exista una única respuesta correcta en los casos en los que las reglas no la determinan. A su juicio, esto sólo sería factible si

\footnotetext{
4 Decisión que tiene una gran trascendencia, pues no está de más recordar que, como escribe Guastini, "en este contexto, "ponderar" no significa atemperar, conciliar o algo por el estilo; es decir, no significa hallar un punto de equilibrio, una solución "intermedia",, que tenga en cuenta ambos principios en conflicto y que -de algún modo- aplique o sacrifique parcialmente a ambos. La ponderación consiste sobre todo en sacrificar o descartar un principio aplicando el otro" (1999, p. 44).
} 
fuese posible un "orden fuerte de principios", esto es, si se pudiera crear una lista completa de los principios de un sistema jurídico y, además, pudieran establecerse todas las relaciones de prioridad abstractas y concretas entre ellos, determinándose así unívocamente la decisión en cada uno de los casos; "si fuera posible una teoría tal de los principios, sería acertada la tesis de Dworkin de la única respuesta correcta" 5 .

Pero este orden fuerte solamente sería posible si el peso de los valores o de los principios y sus intensidades de realización fueran expresables en una escala numérica calculable; no obstante, el problema de semejante orden cardinal fracasa ante los problemas de una medición del peso y de la intensidad de realización de los principios jurídicos o de los valores jurídicos, que sea más que una ilustración de un resultado ya encontrado. Así lo afirma también Rafael de Asís (1994, p. 123), quien, refiriéndose a los derechos fundamentales, sostiene que no es posible, en principio, llevar a cabo una estructuración jerárquica de los derechos en caso de colisión, sino que este problema ha de resolverse en cada caso concreto. Así, por ejemplo, no es posible argumentar que el derecho a la vida es el derecho más fundamental y, por lo tanto, el menos limitado, por ser el presupuesto de los restantes, dado que todo dependerá del significado que se dé a ese derecho y a sus posibles colisiones con otros derechos o bienes constitucionales como, por ejemplo, la libertad. También Zagreblesky (1995, p. 124, 125) sostiene que, por lo general, los principios no se estructuran según una jerarquía de valores, pues si así fuese, se produciría una incompatibilidad con el carácter pluralista de la sociedad, algo inconcebible en las condiciones constitucionales materiales de la actualidad. Ciertamente, en caso de conflicto, el principio de más rango se erigiría en soberano entre todos los demás y sólo permitiría desarrollos consecuentes con él, privando de eficacia a todos los principios inferiores y dando lugar a una "tiranía del valor" esencialmente destructiva.

Ahora bien -volviendo a Alexy (1988, p. 144-148)-, el fracaso de los órdenes fuertes no significa, sin embargo, que no sean posibles teorías de los principios que sean algo más que un mero catálogo de puntos de vista de los que cada uno puede servirse a discreción y que deje la ponderación al arbitrio de quien la realiza. Estas objeciones valen en la medida en que con ellas se infiera que la ponderación no es un procedimiento que, en cada caso, conduzca exactamente a un resultado; pero no valen en la medida en que de ellas se infiera que la ponderación no es un procedimiento racional. Por tanto, lo que sí es posible es un orden débil que consista en tres elementos: un sistema de condiciones de precedencia, un sistema de estructuras de ponderación y un sistema de prioridades prima facie.

Si bien, en tal caso, cabría plantearse si estas normas podrían considerarse plenamente principios, conforme al razonamiento de Prieto Sanchís más arriba expuesto. 
Derecho \& Realidad

El propio Alexy ofrece un ejemplo de cómo surge un sistema de condiciones de precedencia. Se trata del caso Lebach del Tribunal Constitucional alemán (BverfGE, $35,202)$, relativo a una información televisiva repetida, no amparada ya por un interés informativo actual, sobre un delito grave, emitida poco antes de la excarcelación del autor. La argumentación del tribunal se desarrolla en tres niveles: en el primero, constata una colisión entre la protección de la personalidad y la libertad de información; en el segundo nivel establece que bajo una condición determinada y relativamente abstracta, esto es, la de una información actual sobre un delito grave, existe una prioridad de principio o prima facie en favor de la libertad de información; en el tercer nivel decide, finalmente, que bajo cuatro condiciones que se dan en el caso Lebach, a saber, una información repetida, no amparada ya por un interés informativo, sobre un delito grave, que pone en peligro la resocialización del autor, la protección de la personalidad prevalece sobre la libertad de información. Esto significa que tienen validez las consecuencias jurídicas del principio prevaleciente y que, por tanto, la emisión del programa televisivo está prohibida bajo estas condiciones. Pues bien, esta conclusión, puede generalizarse en una ley de colisión que vale para todas las colisiones de principios que reza: "las condiciones bajo las cuales un principio precede a otro constituyen el supuesto de hecho de una regla que expresa la consecuencia jurídica del principio prevalente".

Así, el que las colisiones entre principios deban resolverse mediante ponderación en cada caso concreto no significa que la solución de la colisión sea solamente significativa para ese mismo caso, sino que pueden establecerse relaciones de prioridad que son importantes para la decisión de nuevos casos. Sin embargo, como pueden surgir nuevos casos con nuevas características que deben ser evaluadas, no es posible construir ningún orden que establezca en cada caso justamente una decisión.

Esta objeción lleva a un segundo elemento fundamental de la teoría débil de los principios: la "ley de la ponderación". Como hemos visto, los principios, en cuanto mandatos de optimización, exigen una realización lo más completa posible, en relación con las posibilidades fácticas y jurídicas. Pues bien, la referencia a las posibilidades fácticas lleva a los principios de adecuación o idoneidad y de necesidad. El primero de ellos exige que una medida restrictiva de un derecho no sea admitida si no es adecuada para conseguir la finalidad para la que fue adoptada; el principio de necesidad, por su parte, exige que para que tal medida sea aceptada no puede haber otra medida que sea menos gravosa para el derecho en cuestión y que tenga, al menos, la misma eficacia para conseguir la finalidad perseguida. Por otro lado, la referencia a las posibilidades jurídicas implica una ley de ponderación que puede ser formulada como sigue: "cuanto más alto sea el grado de incumplimiento o de menoscabo de un principio, tanto mayor debe ser la importancia del cumplimiento del otro", lo que no formula otra cosa que el principio de la proporcionalidad en sentido estricto. 
Y el tercer elemento de una teoría débil de los principios lo constituye las prioridades prima facie. Por ejemplo, en una información actual sobre un delito grave, a la libertad de información le corresponde una prioridad prima facie frente a la protección de la personalidad. Las prioridades prima facie establecen cargas de la argumentación, pero si son más fuertes los argumentos en de un principio que juega en sentido contrario, se cumple suficientemente con la misma. De esta manera crean un cierto orden en el campo de los principios, si bien no contienen una determinación definitiva, por lo que el orden depende de nuevo de la argumentación. En definitiva, aunque no es posible una única respuesta correcta, sí lo es un procedimiento de racionalización y justificación de la decisión.

\section{La colisión de derechos en la jurisprudencia constitucional española}

Una vez expuesta la teoría, procede ahora analizar si la práctica y, específicamente, la práctica del Tribunal Constitucional español, se acomoda a aquélla, para lo cual me centraré, especialmente, en su jurisprudencia respecto al muy recurrente conflicto entre los derechos al honor, la intimidad y la propia imagen (art. 18.1 CE), por un lado, y las libertades de expresión e información (art. 20.1), por otro.

Como hemos visto, en el supuesto de una colisión de principios y, más concretamente, de derechos fundamentales, prevalecerá uno u otro en función de las circunstancias. Lo cual se deriva del hecho de que no existen derechos absolutos, que siempre prevalezcan sobre otros, sino que en cada caso de colisión habrá que llevarse a cabo una ponderación de los derechos en juego para determinar cuál de ellos, teniendo en cuenta las circunstancias del caso, prevalecerá en ese caso concreto, si bien en otras ocasiones podrá ceder ante el derecho que ahora se sacrifica.

Y, ciertamente, el Tribunal Constitucional ha dejado bien claro desde sus primeras sentencias que no existen derechos absolutos o ilimitados:

En efecto, no existen derechos ilimitados. Todo derecho tiene sus límites que (...) en relación con los derechos fundamentales, establece la Constitución por sí misma en algunas ocasiones, mientras en otras el límite deriva de una manera mediata o indirecta de tal norma, en cuanto ha de justificarse por la necesidad de proteger o preservar no sólo otros derechos constitucionales, sino también otros bienes constitucionalmente protegidos (STC 2/1982 de 29 de enero F.J. $5^{\circ}$ ).

Ahora bien, si los derechos no son absolutos, tampoco lo son sus límites, como nos recuerda, entre otras muchas, la Sentencia 254/1988 de 21 de diciembre, en su Fundamento Jurídico $3^{\circ}$ : 
Como ya ha declarado en anteriores ocasiones este Tribunal, es cierto que los derechos fundamentales no son absolutos, pero no lo es menos que tampoco puede atribuirse dicho carácter a los límites a que ha de someterse el ejercicio de los mismos. Todas las normas relativas a tales derechos se integran en un único ordenamiento inspirado por los mismos principios; y tanto los derechos individuales como sus limitaciones, en cuanto éstas derivan del respeto a la Ley y a los derechos de los demás, son igualmente considerados por el art. 10.1 de la Constitución como "fundamento del orden político y de la paz social". Se produce así, en definitiva, un régimen de concurrencia normativa, no de exclusión, de tal modo que tanto las normas que regulan el derecho fundamental como las que establecen límites a su ejercicio vienen a ser igualmente vinculantes y actúan recíprocamente. Como resultado de esta interacción, la fuerza expansiva de todo derecho fundamental restringe, por su parte, el alcance de las normas limitadoras que actúan sobre el mismo; de ahí la exigencia de que los límites de los derechos fundamentales hayan de ser interpretados con criterios restrictivos y en el sentido más favorable a la eficacia y a la esencia de tales derechos.

Y tampoco es posible establecer una jerarquía entre los distintos derechos que proporcione una solución a priori, o que permita solucionar las colisiones entre éstos de manera automática por lo que en caso de conflicto habrá siempre que realizar una labor de ponderación. Leemos, así, en el Fundamento Jurídico $2^{\circ}$ de la Sentencia 320/1994 de 28 de noviembre, que:

Queda así, como en otros tantos casos parecidos sometidos a este Tribunal, planteado otra vez el problema de la colisión o encuentro entre derechos y libertades fundamentales (...) La solución consistirá en otorgar la preferencia de su respeto a uno de ellos, justamente aquél que lo merezca, tanto por su propia naturaleza, como por las circunstancias concurrentes en su ejercicio. No se trata, sin embargo, de establecer jerarquías de derechos ni prevalencias a priori, sino de conjugar, desde la situación jurídica creada, ambos derechos o libertades, ponderando, pesando cada uno de ellos, en su eficacia recíproca, para terminar decidiendo y dar preeminencia al que se ajuste más al sentido y finalidad que la Constitución señala, explícita o implícitamente.

También reconoce nuestro Tribunal Constitucional que en ocasiones prevalecerá un derecho y en ocasiones otro en función de las circunstancias concretas del conflicto que se trata de resolver:

Por ello, cuando este derecho fundamental entre en colisión con otros bienes o derechos constitucionalmente protegidos deberán ponderarse los distintos intereses enfrentados $\mathrm{y}$, atendiendo a las circunstancias concretas de cada 
caso, decidir qué interés merece mayor protección, si el interés del titular del derecho a la imagen en que sus rasgos físicos se capten o difundan sin su consentimiento o el interés público en la captación o difusión de su imagen (STC 14/2003 de 28 de enero, F.J. $5^{\circ}$ ).

Por otro lado, esta labor de ponderación entre los derechos o intereses fundamentales en conflicto no corresponde hacerla exclusivamente al T. C., sino a todos y cada uno de los órganos jurisdiccionales a quienes corresponda resolver dicho conflicto:

En consecuencia, cuando del ejercicio de la libertad de expresión e información reconocida en el artículo 20.1 de la C.E. resulte afectado el derecho al honor de alguien, el órgano jurisdiccional está obligado a realizar un juicio ponderativo de las circunstancias concurrentes en el caso concreto, con el fin de determinar si la conducta del agente está justificada por hallarse dentro del ámbito de las libertades de expresión e información y, por tanto, en posición preferente (STC 214/1991 de 11 de noviembre, Fj6).

Si bien no pueden llevar a cabo tal ponderación a su libre albedrío, sino que tienen que ajustarse a las directrices marcadas al efecto por el propio Tribunal Constitucional:

(...) pues lo que se requiere de los órganos jurisdiccionales, en casos como el presente, no es sólo que se ponderen explícitamente, antes de adoptar su decisión, los ámbitos respectivos de los derechos en tensión, sino que dicha ponderación se acomode, como exigencia ya sustantiva, a la propia configuración de tales derechos en la Constitución y en las leyes que los desarrollan, según la interpretación que expresa la doctrina de este Tribunal (STC 20/1992 de 14 de febrero, F.J.2 ${ }^{\circ}$ ).

Y, por supuesto, el máximo tribunal tiene potestad para valorar si ha habido ponderación y si ésta ha sido convenientemente realizada e, incluso, para anular aquellas sentencias con cuya ponderación no esté conforme, dado que ésta no es vinculante para el TC, como vemos en los siguientes ejemplos ${ }^{6}$ :

La cuestión que debe resolver el presente recurso de amparo consiste en verificar si la Sentencia impugnada, al valorar aquella información, llevó a cabo una ponderación y aplicación constitucionalmente adecuada de la libertad de información (art. 20.1 C.E.) y el derecho fundamental al honor (art. 18.1 C.E.) (STC 158/2003 de 15 de septiembre, F.J. $2^{\circ}$ ).

6 Algunas otras sentencias de este tenor: 104/1986, 107/1988, 51/1989, 105/1990, 171/1990, 172/ 1990, 65/1991, 197/1991, 40/1992, 85/1992, 219/1992, 240/1992, 336/1993, 320/1994, 42/1995 76/1995, 78/1995, 176/1995, 204/1997, 134/1999, 180/1999, 297/2000, 49/2001. 
Aunque tal ponderación ha de hacerla, en principio, el órgano jurisdiccional que conozca de las alegadas vulneraciones o intromisiones del derecho al honor, corresponde a este tribunal Constitucional revisar la adecuación de la ponderación realizada por los Jueces y Tribunales ordinarios, con el objeto de determinar si el ejercicio de la libertad reconocido en el artículo 20 cumple con las exigencias del principio de proporcionalidad y se manifiesta o no constitucionalmente legítimo (STC 214/1991 de 11 de noviembre, F. J. $6^{\circ}$ ).

Y es doctrina reiterada de este Tribunal (...) que en los supuestos de conflicto entre el derecho a la libre emisión de información y los derechos al honor, la intimidad y la propia imagen, garantizados en el art. 18.1 CE, la adecuada solución exige que se explicite la toma en consideración de ambos derechos en presencia. Además dicha consideración de uno y otro derecho puede ser realizada por este Tribunal, que no está vinculado por la realizada por la resolución judicial objeto de revisión (STC 76/2002 de 8 de abril, F. J. $2^{\circ}$ ).

Por consiguiente, no basta con que los órganos judiciales hayan efectuado una ponderación entre los bienes constitucionales en presencia, o que ésta pueda tenerse por razonable; esta ponderación, para ser constitucionalmente respetuosa con los derechos fundamentales contenidos en los art. 18.1 y 20.1 C.E., ha de efectuarse de modo que se respete la definición constitucional de los mismos y sus límites, cuya efectiva observancia corresponde verificar a este Tribunal. Dicho en otras palabras, a este Tribunal le compete verificar si los órganos judiciales han hecho una ponderación constitucionalmente adecuada de los derechos fundamentales en conflicto, lo que sólo es posible llevar a cabo por este Tribunal ponderando por sí dichos derechos y comprobar así si la restricción impuesta por los órganos judiciales a uno o a otro está constitucionalmente justificada (STC 112/2000, F.J. $5^{\circ}$ ).

Ciertamente, no son pocas las resoluciones que el T.C. ha anulado por no estar conforme con la ponderación realizada, como en el caso de la Sentencia 286/1993, cuyo Fundamento Jurídico $5^{\circ}$ dice:

Es evidente, y así lo hemos reiterado en numerosas ocasiones, que en el conflicto entre las libertades reconocidas en el art. $20 \mathrm{CE}$ y otros bienes constitucionalmente protegidos, los órganos judiciales deben, habida cuenta las circunstancias del caso, ponderar si la información se ha llevado a cabo dentro del ámbito de dicha protección constitucional o por el contrario si ha transgredido ese ámbito, de forma que siendo inexistente o insuficiente la citada ponderación este Tribunal ha declarado la nulidad de las resoluciones judiciales. 
Pues bien, siendo el papel del Tribunal Constitucional en estos supuestos el valorar si la ponderación efectuada por los órganos judiciales ha sido realizada correctamente o no, hay que concluir que ello no sucede en términos suficientes en la Sentencia impugnada, en cuanto que no se valora o no se hace de forma suficiente la incidencia en la sanción colegial de elementos como el principio de publicidad de los juicios, el papel de los medios de comunicación, el contenido concreto de la información y, en definitiva, el principio de proporcionalidad de los sacrificios, por lo que no cabe sino compartir la apreciación del Ministerio Fiscal en orden a la estimación del recurso de amparo y en consecuencia anular la Sentencia impugnada.

No obstante, lo más frecuente no es que el Tribunal Constitucional anule resoluciones judiciales por no estar de acuerdo con la ponderación realizada, sino, sencillamente, porque no ha habido tal ponderación; valga como ejemplo de todas ellas la siguiente sentencia ${ }^{7}$ :

Así, pues, en el caso que nos ocupa, partiendo del análisis de los hechos y de la legalidad penal aplicable, resulta forzoso para el juzgador realizar esa ponderación entre, por un lado, la lesión invocada por el denunciante como producida a su derecho al honor y constitutiva, a su entender de un hecho antijurídico, típico y punible, y, por otro lado, el derecho fundamental del art. 20.1 de la Constitución reiteradamente citado por el denunciado en todos sus escritos y comparecencias como justificativo de su acción.

En esa obligada ponderación, el juez penal debió valorar, desde luego, el contenido mismo del artículo periodístico, la mayor o menor intensidad de sus frases, su tono humorístico, el hecho de afectar al honor del denunciante, no en su faceta íntima o privada, sino en cuanto derivara solo de su gestión pública como titular de un cargo representativo y la intención de la crítica política en cuanto formadora de la opinión pública, así como también la inexistencia o la existencia del animus injuriandi. Una vez realizada por los Jueces del orden penal esta ponderación, esto es, introduciendo por fuerza en el enjuiciamiento del factum legal la perspectiva constitucional en torno a los derechos fundamentales en juego, este Tribunal Constitucional poco tendría que decir (...).

\footnotetext{
7 Son innumerables las ocasiones en las que el Tribunal Constitucional ha dejado sin efecto resoluciones judiciales por falta de ponderación o por ser ésta deficiente así, entre otras muchas: SSTC 104/1986, 107/1988, 37/1989, 51/1989, 201/1990, 65/1991, 214/1991, 123/1992, 223/1992, 227/1992, 151/1993, 286/1993, 99/1994, 8/2000, 11/2000, 136/2000, 148/2001, 76/2002, 54/2004. $E$ incluso ha llegado a declarar inconstitucionales algunos preceptos legales por falta de una ponderación entre los valores constitucionales afectados por los mismos, como es el caso del párrafo $1^{\circ}$ del artículo 133 de la Ley 11/1981 de modificación del Código Civil, por entender que vulneraba el derecho a la igualdad ante la ley y el derecho a la tutela judicial efectiva (STC 273/2005 de 27 de octubre, F.J. $7^{\circ}$ ).
} 
En el caso presente, lo que nos lleva al otorgamiento del amparo no es una discrepancia respecto a la ponderación de bienes y derechos fundamentales, sino la inexistencia de tal ponderación por parte del juez de instrucción en su segunda Sentencia de apelación (...).

El juez de apelación en su Sentencia de 29 de marzo de 1985, protegió la fama y el respeto debido a la autoridad criticada, pero lo hizo desde una perspectiva jurídica incompleta, ya que en la fundamentación de la decisión no incluyó (o más bien excluyó, puesto que la libertad del art. 20 de la Constitución había sido alegada y aun utilizada por la Sentencia apelada) el examen de la concurrencia y posibles efectos justificativos de la libertad de opinión y de información. Al omitir indebida e inexcusablemente de su enfoque tal derecho fundamental lo desconoció, y al desconocerlo voluntaria y conscientemente, lo vulneró, por todo lo cual su Sentencia debe ser anulada (STC 104/1986 de 17 de julio, F.J. $6^{\circ}$ ).

Ahora bien, ¿en qué consiste exactamente esta ponderación que exige el Tribunal Constitucional y que él mismo aplica en el caso de colisión de derechos? Pues bien, como hemos visto, la ley de ponderación consistía, según Alexy, en llevar a cabo un juicio de proporcionalidad entre los derechos enfrentados (o entre un derecho y un valor constitucional o una medida administrativa o judicial presuntamente protectora de un bien o interés público) que incluya la aplicación de los tres subprincipios de adecuación, necesidad y proporcionalidad en sentido estricto (lo que se ha venido en llamar el "test alemán de proporcionalidad").

En este sentido, Markus González (2003, p. 16), en su exhaustivo estudio sobre la aplicación del principio de proporcionalidad por parte del Tribunal Constitucional español, señala que desde sus primeras sentencias pueden encontrarse múltiples referencias a dicho principio ${ }^{8}$, especialmente en el ámbito de las colisiones de derechos fundamentales. No obstante, tradicionalmente dicho Tribunal ha venido empleando este principio con cierta generalidad e indeterminación y recurriendo casi exclusivamente al principio de proporcionalidad en sentido estricto, al que ha utilizado como sinónimo de ponderación ${ }^{9}$. Así, por ejemplo, en la sentencia 85/ 1992 de 8 de junio, leemos que:

\footnotetext{
8 Así, por ejemplo la STC 22/1981 (sobre la jubilación forzosa a los 69 años) donde se habla de la "razonable relación de proporcionalidad entre los medios empleados y la finalidad perseguida" que debe existir para que una diferencia de trato no derive en discriminación o la STC 26/1981 (servicios mínimos huelga de RENFE) donde se hace mención de la "regla de proporcionalidad de los sacrificios" como criterio para determinar si unos servicios mínimos pueden considerarse abusivos o no.

9 Véanse, entre otras, las SSTC 26/1981, 62/1982, 13/1985, 66/1985, 178/1985, 53/1986, 65/1986, 19/1988, 37/1989, 6/1991, 85/1992, 158/1993, 85/1994, 50/1995, 126/1995, 181/1995, 49/1996, 54/1996, 49/1999, 69/1999, 166/1999, 126/2000, 154/2002, 195/2003.
} 
En este punto es importante destacar que, al efectuar la ponderación debe tenerse también presente la relevancia que en la misma tiene el criterio de la proporcionalidad como principio inherente del Estado de Derecho cuya condición de canon de constitucionalidad, reconocida en Sentencias del más variado contenido tiene especial aplicación cuando se trata de proteger derechos fundamentales frente a limitaciones o constricciones, procedan estas de normas o resoluciones singulares, y así lo declara la STC 37/89, en la que se hace referencia a la reiterada doctrina según la cual la regla de la proporcionalidad de los sacrificios es de observancia obligada al proceder a la limitación de un derecho fundamental, doctrina que nos conduce a negar legitimidad constitucional a las limitaciones o sanciones que incidan en el ejercicio de los derechos fundamentales de forma poco comprensible, de acuerdo con una ponderación razonada y proporcionada de los mismos y a exigir que toda acción deslegitimadora del ejercicio de un derecho fundamental adoptada en protección de otro derecho fundamental que se enfrente a él sea equilibradora de ambos derechos y proporcionada con el contenido y finalidad de cada uno de ellos (F.J. $4^{\circ}$ ).

Sin embargo, en los últimos años esta situación ha cambiado y el Tribunal ha empezado a formalizar este principio a través de los requisitos de idoneidad, necesidad y proporcionalidad en sentido estricto que, como este mismo autor nos recuerda, son los que desde hace décadas vienen utilizando la doctrina y la jurisprudencia constitucional alemanas para llenar de contenido el principio de proporcionalidad $-\mathrm{y}$ que en nuestros días está siendo utilizado por prácticamente todos los Tribunales Constitucionales europeos- ${ }^{10}$.

La primera sentencia en la que el TC alude expresa y conjuntamente a los tres requisitos de idoneidad, necesidad y proporcionalidad en sentido estricto como integrantes del principio de proporcionalidad es la 66/1995 de 8 de mayo -si bien ni en ésta ni en ninguna posterior ha reconocido explícitamente la influencia ni de la doctrina ni de la jurisprudencia alemanas- Así, en el Fundamento Jurídico 5º, dicha sentencia proclama que:

Para comprobar si la medida impeditiva del ejercicio del derecho de reunión supera el juicio de proporcionalidad exigible, es necesario constatar si cumple los siguientes tres requisitos o condiciones: si tal medida era susceptible de conseguir el objetivo propuesto -la garantía del orden público sin peligro para

10 Esta utilización expresa y sucesiva de los tres requisitos puede encontrarse, entre otras, en las SSTC 66/1995, 55/1996, 207/1996, 270/1996, 123/1997, 151/1997, 161/1997, 175/1997, 200/1997, 37/1998, 66/1998, 177/1998, 18/1999, 69/1999, 139/1999, 98/2000, 136/2000, 186/2000, 265/2000, 156/2001, 14/2003 ó 11/2006. 
personas y bienes-; si, además, era necesaria en el sentido de que no existía otra medida más moderada para la consecución de tal propósito con igual eficacia, y, finalmente, si la misma era proporcionada en sentido estricto, es decir, ponderada o equilibrada por derivarse de ella más beneficios o ventajas para el interés general que perjuicios sobre otros bienes o valores en conflicto.

Más explícitamente aun lo proclama la Sentencia 207/1996 de 16 de diciembre:

Según doctrina reiterada de este Tribunal, una exigencia común y constante para la constitucionalidad de cualquier medida restrictiva de derechos fundamentales (...) viene determinada por la estricta observancia del principio de proporcionalidad (...).

En este sentido hemos destacado que para comprobar si una medida restrictiva de un derecho fundamental supera el juicio de proporcionalidad, es necesario constatar si cumple los tres siguientes requisitos o condiciones: si tal medida es susceptible de conseguir el objetivo propuesto (juicio de idoneidad); si, además es necesaria, en el sentido de que no exista otra medida más moderada para la consecución de tal propósito con igual eficacia (juicio de necesidad); $\mathrm{y}$, finalmente, si la misma es ponderada o equilibrada, por derivarse de ella más beneficios o ventajas para el interés general que perjuicios sobre otros bienes o valores en conflicto (juicio de proporcionalidad en sentido estricto). Así pues para que una intervención corporal en la persona del imputado en contra de su voluntad satisfaga las exigencias del principio de proporcionalidad será preciso: a) que sea idónea (apta, adecuada) para alcanzar el fin constitucionalmente legítimo perseguido con ella, esto es, que sirva objetivamente para determinar los hechos que constituyen el objeto del proceso penal; b) que sea necesaria o imprescindible para ello, esto es, que no existan otras medidas menos gravosas que, sin imponer sacrificio alguno de los derechos fundamentales a la integridad física y a la intimidad, o con menor grado de sacrificio, sean igualmente aptas para conseguir dicho fin, y c) que, aun siendo idónea y necesaria, el sacrificio que imponga de tales derechos no resulte desmedido en comparación con la gravedad de los hechos y de las sospechas existentes (F.J. $4^{\circ}$ ).

Sin embargo, estas primeras sentencias no supusieron la consolidación definitiva del "test alemán de proporcionalidad", pues el T. C. continuó aplicando alternativamente el principio de proporcionalidad tal y como lo había venido haciendo anteriormente, sin formalizarlo o empleando sólo alguno de sus elementos. A pesar de ello, puede sostenerse que dicho test constituye hoy uno de los criterios de interpretación que con mayor frecuencia ha empleado la jurisprudencia constitucional española, sobre todo en el ámbito de los derechos fundamentales 
El ámbito en el que normalmente y de forma muy particular resulta aplicable el principio de proporcionalidad es el de los derechos fundamentales. Así ha venido reconociéndolo este tribunal en numerosas Sentencias en las que se ha declarado que las desproporción entre el fin perseguido y los medios empleados para conseguirlo puede dar lugar a un enjuiciamiento desde la perspectiva constitucional cuando esa falta de proporción implica un sacrifico excesivo e innecesario de los derechos que la Constitución garantiza (...) Esta constatación no significa que en algún supuesto concreto no pueda argumentarse a partir del principio de proporcionalidad para concluir en la infracción de otro tipo de preceptos constitucionales. Pero, en todo caso, como queda dicho, siempre deberá indagarse, no la sola existencia de una desproporción entre medios y fines, sino en qué medida estos preceptos resultan vulnerados como consecuencia de la citada desproporción (STC 55/1996 de 28 de marzo, F. J. $2^{\circ}$ ).

Como consecuencia de la aplicación del llamado "test alemán de proporcionalidad", nuestro Tribunal Constitucional ha dejado sin efecto numerosas sentencias judiciales y medidas administrativas que, a su juicio, no lo superaban ${ }^{11}$. Un ejemplo relativamente reciente lo encontramos en la Sentencia 14/2003 de 28 de enero:

No puede deducirse del art. 18.1 CE que el derecho a la propia imagen, en cuanto límite al obrar ajeno, comprenda el derecho incondicionado y sin reservas de impedir que los rasgos físicos que identifican a la persona se capten o se difundan. El derecho a la propia imagen, como cualquier otro derecho, no es un derecho absoluto, y por ello su contenido se encuentra delimitado por el de otros derechos y bienes constitucionales (...) No obstante, como ya se ha señalado, existen circunstancias que pueden conllevar que la regla enunciada ceda, lo que ocurrirá en los casos en que exista un interés público en la captación o difusión de la imagen, y este interés público se considere constitucionalmente prevalente al interés de la persona en evitarlas (...).

Puede acontecer así que, a pesar de haberse producido una intromisión en el derecho del demandante en amparo a la propia imagen, la misma no resulte ilegítima si se revela como idónea y necesaria para alcanzar un fin constitucionalmente legítimo, proporcionada para lograrlo y se lleva a cabo utilizando los medios necesarios para procurar una mínima afectación del ámbito garantizado por el derecho fundamental (...).

La adopción de una medida como la cuestionada requería ponderar, adecuadamente y de forma equilibrada, de una parte, la gravedad de la intromisión que comportaba, en lo que ahora interesa, en el derecho a la

$\overline{11}$ Algunos casos: SSTC 37/1998, 136/1999, 136/2000, 89/2006 y 90/2006. 
Derecho ₹ Realidad

propia imagen del recurrente en amparo, y de otra parte, si la medida era idónea, necesaria, imprescindible y proporcionada para asegurar la defensa del interés público que pretendía proteger (...).

Pues bien, en el presente caso, no puede estimarse que la intromisión que ha padecido el recurrente de amparo en su derecho a la propia imagen se encuentre justificada por los distintos bienes constitucionales e intereses públicos aducidos por la Jefatura Superior de Policía de Valladolid la Sentencia de la Audiencia Nacional y por el Abogado del Estado y el Ministerio Fiscal en sus escritos de alegaciones. Por el contrario, tal medida no se revela como idónea, necesaria ni proporcionada para alcanzar aquellos bienes o intereses que se dicen perseguir con la difusión a determinados medios de comunicación de la reseña fotográfica policial del demandante de amparo.

Por otra parte, el Tribunal Constitucional español no reconoce derechos con prioridad prima facie, pero sí derechos que gozan de una protección especial, si bien para ello deben darse ciertos requisitos. Estaríamos, así, ante lo que Alexy denomina "sistemas de condiciones de precedencia" o "relación de prevalencia condicionada" (a diferencia de las relaciones de prevalencia incondicionadas o absolutas, en virtud de las cuales un derecho siempre se impone a otro, lo que, como hemos visto, no admite este Tribunal).

Esta relación de prevalencia condicionada consiste -recordemos- en que, teniendo en cuenta el caso, se indican las condiciones bajo las cuales un principio (o, en este caso, un derecho) precede a otro, si bien, bajo otras condiciones, la cuestión de la precedencia puede ser solucionada de manera inversa. De este modo, la solución a una determinada colisión puede no ser relevante sólo para ese caso concreto, sino que podrá fijar relaciones de prioridad aplicables a nuevos casos. Buen ejemplo de ello es la Sentencia 158/2003 de 15 de septiembre, en cuyo Fundamento Jurídico $3^{\circ}$ leemos que:

Este Tribunal ha elaborado un cuerpo consolidado de doctrina en los casos en que exista un conflicto entre el derecho a la libertad de información y el derecho al honor (...). Dicha doctrina parte de la posición especial que en nuestro ordenamiento ocupa la libertad de información, puesto que a través de este derecho no sólo se protege un interés individual, sino que entraña el reconocimiento y garantía de la posibilidad de existencia de una opinión pública libre, indisolublemente unida al pluralismo político propio del Estado democrático. El valor preferente o prevalente de este derecho ha sido, sin embargo relativizado en nuestra jurisprudencia negando su jerarquía sobre otros derechos fundamentales. De ahí que hayamos condicionado la protección constitucional de la libertad de información y su prevalencia sobre el derecho al honor garantizado en el artículo 18.1 CE, a que la información se refiera a 
hechos de relevancia pública, en el sentido de noticiables, y a que dicha información sea veraz ${ }^{12}$.

De modo que la ley de colisión que en abstracto rezaba "las condiciones bajo las cuales un principio precede a otro constituyen el supuesto de hecho de una regla que expresa la consecuencia jurídica del principio prevalente", puede transformarse, en este caso, en una regla que disponga que: "cuando se emita una información veraz y referida a hechos de relevancia pública, el derecho a la información del emisor deberá prevalecer en todo caso, incluso ante el derecho al honor de la persona a quien se refiere tal información"; y esta regla habrá de ser aplicada en todos los supuestos de colisión entre los referidos derechos ${ }^{13}$.

Son muchas las resoluciones en las que, aplicando esta ley de colisión el Tribunal Constitucional ha dado prevalencia al derecho a informar respecto a los derechos al honor, la intimidad o la propia imagen. Sin embargo, parece más interesante citar algún ejemplo de supuestos en los que éstos últimos han prevalecido como consecuencia de no darse, precisamente, alguna de las condiciones de prevalencia, por lo que no era de aplicación la consecuencia jurídica de dicha regla.

Así, el T. C. en su sentencia 115/2000, de 10 de mayo, entendió que no había lugar a la prevalencia del derecho a la información porque la misma no tenía relevancia pública. En este caso se trataba de dirimir si una información aparecida

12 Esta relación de prioridad o prevalencia entre el derecho a informar y el derecho al honor, la intimidad y la propia imagen es una constante en nuestra jurisprudencia constitucional prácticamente desde sus inicios, si bien he optado por ejemplificarla con una resolución tan reciente, por ser ésta la que quizás la ha expresado más claramente. No obstante, es también importante la muy temprana sentencia 6/1981 de 14 de marzo, donde se profundizaba un tanto en la razón de la relevancia del derecho a la información: "El art. 20 de la Constitución, en sus distintos apartados, garantiza el mantenimiento de una comunicación pública libre, sin la cual quedarían vaciados de contenido real otros derechos que la Constitución consagra, reducidas a formas hueras las instituciones representativas y absolutamente falseado el principio de legitimidad democrática que enuncia el art. 1.2 de la Constitución, y que es la base de toda nuestra ordenación jurídico-política" (F.J. $3^{\circ}$ ). También es relevante, en este sentido, la sentencia 159/1986 de 16 de diciembre: "es preciso destacar, por lo que se refiere al precepto constitucional en que se apoya el presente recurso, que el art. 20 de la Norma fundamental, además de consagrar el derecho a la libertad de expresión y a comunicar o recibir libremente información veraz, garantiza un interés constitucional: la formación y existencia de una opinión pública libre, garantía que reviste una especial trascendencia ya que, al ser una condición previa y necesaria para el ejercicio de otros derechos inherentes al funcionamiento de un sistema democrático, se convierte, a su vez, en uno de los pilares de una sociedad libre y democrática. Para que el ciudadano pueda formar libremente sus opiniones y participar de modo responsable en los asuntos públicos, ha de ser también informado ampliamente de modo que pueda ponderar opiniones diversas e incluso contrapuestas" (F.J. $6^{\circ}$ ).

13 Son muchas otras las sentencias que expresan claramente esta relación de prevalencia, entre ellas, las SSTC: 105/1983, 51/1985, 104/1986, 6/1988, 107/1988, 105/1990, 171/1990, 172/1990 143/1991, 214/1991, 40/1992, 85/1992, 219/1992, 223/1992, 240/1992, 123/1993, 178/1993, $232 /$ 1993, 320/1994, 22/1995, 78/1995, 132/1995, 138/1996, 144/1998, 21/2000, 112/2000, 49/2001, 76/2002, 54/2004. 
en una publicación periódica referente a ciertos hechos y situaciones de la vida privada de un personaje público, así como a su hogar y los modos de vida de quienes convivían en el mismo. La recurrente consideraba que el reportaje entrañaba una intromisión ilegítima en su intimidad personal y familiar ${ }^{14}$. Al respecto, la citada resolución judicial afirmaba que:

Si la libertad de información se ejerce sobre un ámbito que afecta a otros bienes constitucionales, en este caso, los de la intimidad y dignidad de la persona, para que su proyección sea legítima es preciso que lo que se comunica resulte de interés público, pues sólo entonces puede pedirse a aquéllos que afecta o perturba el contenido de la información que pese a ello la soporten en aras, precisamente, del conocimiento general y difusión de los hechos y situaciones que interesan a la comunidad (F.J. $7^{\circ}$ ).

Teniendo en cuenta las conclusiones alcanzadas en los dos fundamentos jurídicos anteriores, el problema de constitucionalidad radica, pues, en el interés general de la información, que la entidad mercantil que edita la revista (...) vincula a la proyección pública que posee la recurrente en amparo. Y cierto es que ésta es una persona con notoriedad pública por diversas razones, entre ellas su frecuente presencia en los medios de comunicación exponiendo al conocimiento de terceros su actividad profesional o determinados aspectos de su vida privada. Por lo que cabe incluirla en el grupo de aquellos sujetos que, junto con quienes tienen atribuidas la administración del poder público, por su actividad asumen un mayor riesgo frente a informaciones que les conciernen (...). No toda información que se refiere a una persona con notoriedad pública goza de esa especial protección, sino que para ello es exigible, junto a ese elemento subjetivo del carácter público de la persona afectada, el elemento objetivo de que los hechos constitutivos de la información, por su relevancia pública, no afecten a la intimidad, por restringida que ésta sea.

El criterio determinante es la relevancia para la comunidad de la información que se comunica. Esto es, si nos encontramos ante unos hechos o circunstancias susceptibles de afectar al conjunto de los ciudadanos, lo que posee un indudable valor constitucional; y es distinto, ya sea de la simple satisfacción de la curiosidad humana en la vida de otros, potenciada en nuestra sociedad tanto por determinados medios de comunicación como por ciertos programas o secciones de otros, o bien de lo que a juicio de uno de estos medios puede resultar noticioso en un determinado momento (F.J. $9^{\circ}$ ).

14 Otras sentencias en las que el T. C. no concede prioridad al derecho a informar por entender que los datos revelados no tienen relevancia pública: SSTC 165/1987, 171/1990, 197/1991, 214/1991, 40/ 1992, 85/1992, 320/1994, 22/1995, 112/2000. 
En el presente caso, basta la simple lectura del reportaje aquí considerado para estimar que los datos divulgados carecen de relevancia pública (...). Lo que entraña, en consecuencia, que dicho reportaje no puede encontrar amparo en el derecho fundamental a comunicar libremente información, sino que constituye, por el contrario, una intromisión ilegítima en la esfera de intimidad de la recurrente constitucionalmente garantizada (F.J. 10).

\section{Conclusión}

Vemos, pues, que nuestro Tribunal Constitucional aplica los criterios de resolución de colisiones de derechos sistematizados y expuestos por Alexy y que trata de resolver dichas colisiones conforme a un procedimiento racional y justificado. No obstante, como señala Cabra Apalategui (2000, p. 170), este sistema no conduce a un resultado definitivo, únicamente dice qué es lo que hay que fundamentar para justificar el enunciado de preferencia condicionado que representa el resultado de la ponderación, pero ésta deja todavía margen a valoraciones cuyo control racional escapa al propio procedimiento de ponderación. Es por ello por lo que, a juicio de Alexy, estos déficit de racionalidad de la ley de la ponderación requieren el complemento de una teoría de la argumentación jurídica racional de mayor alcance.

También Prieto Sanchís (2000, p. 181) sostiene que si bien la ponderación no equivale a irracionalidad, no significa tampoco que su resultado sea el fruto de la mera aplicación de normas, esto es, el que represente un ejercicio de racionalidad no supone que sus conclusiones vengan impuestas por el Derecho; "es una operación racional, pero una operación que en lo esencial se efectúa sin "red normativa”, a partir de valoraciones en las que no tiene por qué producirse un acuerdo intersubjetivo", pues "decidir que el sacrificio circunstancial de un principio merece la pena desde la perspectiva de la satisfacción de otro entraña sin duda una valoración, valoración en la que -aunque no se quiera- pesará la importancia que cada individuo concede a los respectivos bienes en conflicto, así como su propia "cuantificación" de costes y beneficios en el caso concreto".

En definitiva, es posible afirmar que lo que parecen hacer los principios constitucionales es justamente cercenar la discrecionalidad del legislador, pues en el esquema del constitucionalismo contemporáneo el sistema queda saturado mediante los principios, con la particularidad de que estos principios, que antes han limitado la libertad política del legislador, se muestran después como dúctiles instrumentos en manos del juez. La conclusión puede formularse así: "la rematerialización de la Constitución a través de los principios supone un desplazamiento de la discrecionalidad desde la esfera legislativa a la judicial: bien es verdad que no se trata ya de la misma discrecionalidad, y la diferencias es esencial: la del legislador ha sido siempre una discrecionalidad inmotivada, mientras que la del juez pretende 
venir domeñada por una depurada argumentación racional" (Prieto Sanchís, 2000, p. 173).

Es por esto por lo que podemos concluir, con Javier Ansuátegui (2006, p. 554), que la lógica del constitucionalismo y de las exigencias limitativas del poder que le son consustanciales, impone al juez la obligación de poner un especial empeño a la hora de motivar su decisión, a la hora de explicar cuáles son las razones que ha tenido en cuenta en su razonamiento intelectual y que le han llevado a adoptar una concreta y determinada decisión, en contra de otras posibilidades. Asimismo, la razonabilidad, entendida como elemento básico del test de aceptabilidad al que debe ser sometida la decisión judicial es, en este sentido, una de las manifestaciones que presenta la seguridad jurídica en el constitucionalismo contemporáneo.

\section{Referencias}

Aarnio, A. (2000). Reglas y principios en el razonamiento jurídico. Anuario da Facultade de Dereito da Universidade da Coruña, (4).

Alexy, R. (1988). Sistema jurídico, principios jurídicos y razón práctica. Doxa, (5).

Alexy, R. (1997). Teoría de los derechos fundamentales. trad. de E. Garzón. Madrid: C.E.C.

Alexy, R. (1997). El concepto y validez del Derecho, trad. de J. M. Seña. Barcelona: Gedisa.

Alexy, R. (2000, sep.). On the structure of legal principles. Ratio Juris, 13 (3).

Ansuátegui, J. (2006). Creación judicial del derecho: critica de un paradigma. En El derecho en red. Estudios en homenaje al profesor Mario G. Losano. Madrid: Dykinson.

Arjona, C. (2003). Afinidades entre Dworkin y Pound. Un breve estudio sobre influencias y coincidencias. Doxa, (26).

Asís, R. (1994). Sobre los límites de los derechos. Derechos y libertades, (3).

Asís, R. (1995). Jueces y normas. La decisión judicial desde el ordenamiento. Madrid: Marcial Pons.

Atienza, M. \& Ruiz, J. (1991). Sobre principios y reglas. Doxa, (10).

Atienza, M. \& Ruiz, J. (1996). Las piezas del derecho. Barcelona: Ariel. 
Betegón, J. et al. (1997). Lecciones de teoría del derecho. Madrid: McGraw-Hill.

Cabra, J. M. (2000). Racionalidad y argumentación jurídica. Derechos y libertades, (9).

Díaz, R. (1997). Teoría general del derecho. Madrid: Tecnos.

Dworkin, R. (1995). Los derechos en serio. Ariel, Barcelona: Ariel.

Garzón, E. \& Laporta, F. J. (eds.). (1996). El Derecho y la justicia. Madrid: Trotta-CSIC-BOE.

González, M. (2003). El principio de proporcionalidad en la jurisprudencia del Tribunal Constitucional. Cizur Menor, Navarra: Aranzadi.

Guastini, R. (1999). Principios de derecho y discrecionalidad judicial, trad. de P. Andrés Ibáñez. Jueces para la democracia, (34).

Hart, H.L.A. (1990). El concepto de Derecho, trad. de G. Carrió. Buenos Aires: Abeledo-Perrot.

kelsen, h. (1983). Teoría general del Derecho y del Estado, trad. de E. García Maynez. México: UNAM.

Orozco, J. (2003, abril). Consideraciones sobre los principios y las reglas en el derecho electoral mexicano. Isonomía, (18).

Peces-Barba, G. (1997). Prólogo a Santamaría Ibeas, J. Javier: Los valores superiores en la jurisprudencia del Tribunal Constitucional. Madrid: Universidad de Burgos-Dykinson.

Prieto Sanchís, L. (1997). La doctrina de los principios generales del derecho y la distinción entre principios y reglas. En Betegón, J. et al. Lecciones de teoría del derecho. Madrid: McGraw-Hill.

Prieto Sanchís, L. (1998). Ley, principios, derechos. Cuadernos Bartolomé de las Casas, $\mathrm{n}^{0}$ 7. Madrid: Dykinson.

Prieto Sanchís, L. (2000). Tribunal Constitucional y positivismo jurídico. Doxa, (23).

Rodríguez, J. M. (2004). Principios del derecho y razonamiento jurídico. Madrid: Dykinson.

Ruiz, J. Principios jurídicos. En E. Garzón \& F.J. Laporta (eds.). El derecho y la justicia. Madrid: Trotta-CSIC-BOE. 
Saavedra, M. (1994). Interpretación del derecho y crítica jurídica. México: Fontamara.

Santamaría, J. J. (1997). Los valores superiores en la jurisprudencia del Tribunal Constitucional. Madrid: Universidad de Burgos-Dykinson.

Zagreblesky, G. (1995). El derecho dúctil. Ley, derechos, justicia, trad. de M. Gascón. Madrid: Trotta. 